D. João's Government and the Slave

\title{
0 Governo de D. João e o Tráfico de Escravos: A convenção de 1817 e a sua repercussão na América Portuguesa
}

Trade: the 1817 Convention and its

repercussion in Portuguese America

\section{Guilherme de Paula Costa Santos}

Mestrando em História na

Universidade de São Paulo
1

Pesquisa integrada ao Projeto Temático Estado e Nação Brasileiros, sob orientação de Cecilia Helena de Salles Oliveira.

\section{Resumo}

Esta pesquisa analisa a elaboração e as repercussões da Convenção de 1817 assinada entre os governos português e britânico com o objetivo de regulamentar as disposições do Tratado de 22 de janeiro de 1815 para a abolição do tráfico de escravos ao Norte do Equador. A partir dessa assinatura, pretendemos reconstituir a discussão política do governo joanino frente à questão do tráfico; as implicações econômicas e sociais da Convenção no Império Português; bem como mapear interesses e influências políticas de diversos grupos mercantis envolvidos no tráfico Atlântico, no período entre 1815-1821.

\section{Abstract}

This research analyses the Convention of 1817, signed by Portuguese and British governments in order to settle some articles of the 1815's Treaty that determined the abolition of the slave trade North of the Equator. By discussing the Convention we intend not only to reenact the political debate on slave trade, but also the social and economical consequences of the Convention on the Portuguese Empire and the interests of trans-atlantics groups involved in that commerce.

\section{Palavras-chaves}

Portugal, Inglaterra, tráfico negreiro, abolição do tráfico africano

\section{Keywords}

Portugal, England, slave trade, abolition of the African slave trade 
Guilherme de Paula Costa Santos. A Reorganização do Estado Português na América (1808-1815): estudo do acervo do Museu Paulista/USP, Relatório de Pesquisa em Iniciação Científica PIBIC/CNPq/USP, Museu Paulista, 2003

3

Coleção Alberto Penteado (Coleção de Leis, Decretos e A/varás), Biblioteca do Museu Paulista/USP, Obras Raras.

Robert Conrad, no primeiro capitulo de Tumbeiros (O tráfico de escravos no Brasil). São Paulo: Brasiliense, 1985, exibe várias estatísticas em torno da entrada de africanos nos portos brasileiros. Seja qual for a ordem de grandeza, todas as cifras denotam uma curva de crescimento na importação de escravos nos anos em que a América era a sede da Monarquia Lusitana. Cap 1, pp. 34-43. Ver também: Manolo G. Florentino. Em Costas Negras: uma história do tráfico de escravos entre África e o Rio de Janeiro: séculos XVIII e XIX. São Paulo: Cia das Letras, 1997, Gráfico 4, p. 46; Tabela 3, p. 51; e, por fim, Tabela 5, p. 61.
0 estudo da política adotada pela Corte do Rio de Janeiro em relação ao tráfico de escravos, a partir da assinatura da Convenção de 1817, nasceu da pesquisa realizada em Iniciação Científica durante os anos de 2002 e 20032. Durante este biênio, o trabalho pôde delinear a conduta política da Corte lusitana diante das grandes redes de interesses mercantis no Atlântico-Sul, identificando pressões de "portugueses" estabelecidos na América; de "portugueses" estabelecidos em Portugal, mas com empreendimentos na América; e interesses de estrangeiros, especialmente ingleses, nas rotas atlânticas do império português.

A documentação utilizada para a elaboração do Relatório de Iniciação Cientifica, denominada Coleção Alberto Penteado 3 , possibilitou evidenciar a colisão dos interesses de cada grupo - embora nem sempre articulados - na busca de melhores vantagens mercantis nas rotas do Atlântico-Sul. Cabia, então, ao gabinete do Rio de Janeiro conduzir as pressões desses negociantes e administrar os conflitos gerados pelos diversos embates de interesses de um ou outro grupo.

Ao reconhecer a teia de interesses imersa às rotas do Atlântico-Sul, identificamos um paradoxo na linha política adotada pela Corte no Rio: ao longo da segunda década do século XIX, enquanto o gabinete de D. João assumia compromissos com a Grã-Bretanha para abolir, sempre gradualmente, o comércio da escravatura, aumentava a entrada de africanos na América Portuguesa4.

Foi, portanto, a partir da constatação inicial de uma postura "dúbia" da Corte do Rio de Janeiro que avançamos a pesquisa em nível de Mestrado com o objetivo de analisar a política posta em prática pelo governo joanino frente ao tráfico de escravos. Especificamente, o trabalho se propôs a estudar a negociação referente à ratificação da Convenção Adicional ao Tratado de 1815, assinada em 1817, que concedia à Grã-Bretanha entre outras disposições: o direito de visita aos navios suspeitos de praticarem comércio de escravos ao norte da linha do Equador; o estabelecimento de tribunais mistos em Serra Leoa e no Rio de Janeiro para julgar navios apresados sob suspeita de praticarem tráfico nas zonas proibidas; e regularizava as disposições tomadas entre Portugal e Grã-Bretanha, presentes no Tratado de 1815, elaborado durante Congresso de Viena, para solucionar embates entre traficantes portugueses e oficiais da marinha britânica desde o início da década de dez do século XIX.

\section{Fontes utilizadas para o desenvolvimento da pesquisa}

As principais fontes utilizadas para o desenvolvimento da pesquisa pertencem ao acervo da Seção de Manuscritos da Biblioteca Nacional, ao acervo do Arquivo Histórico do Itamaraty - ambos situados no Rio de Janeiro - e aos acervos da Biblioteca do Instituto de Estudos Brasileiros da Universidade de São Paulo.

Grande parte da documentação da Seção de Manuscritos da Biblioteca Nacional é composta pela correspondência de Thomas Vilanova Portugal, Secretário dos Negócios Estrangeiros e da Guerra, em 1817, destinada aos diversos embaixadores e plenipotenciários da Monarquia Portuguesa, a exemplo do Conde de Palmela, D. Pedro de Sousa Holtein, e o Conde de Funchal, D. Domingos de Sousa Coutinho.

Já as fontes localizadas no Arquivo Histórico do Itamaraty pertencem à Legação Portuguesa em Londres, de 1816 a 1819, e resumem-se aos 
O Investigador Portuguez em Inglaterra, Londres, 1811-1819. (22 vols) e Correio Braziliense ou Armazém Literário, Londres, 1808-1823. (29vols). As duas coleções se encontram na biblioteca do Instituto de Estudos brasileiros da USP (IEB/USP).

6

Ver: PANTALEÃO, Olga. "O Reconhecimento do Império: a mediação inglesa". In: HOLANDA, Sérgio Buarque de. História Geral da Civilização Brasileira $4^{a}$ ed. Rio de Janeiro: Difel, 1976; Tomo II, Vol. 1; COSTA, Emilia Viotti da. Da Monarquia à República: momentos decisivos. 7a ed. São Paulo: Fundação Editora Unesp, 1999; BETHELL, Leslie. A Abolição do Trafico de Escravos no Brasil: a Grã-Bretanha, o Brasil e a Questão do Tráfico de Escravos de 1807-1869. Rio de Janeiro: expressão e cultura; São Paulo: Edusp, 1976; CONRAD, Robert C.. Tumbeiros. O tráfico de escravos para o Brasil. São Paulo: Brasiliense, 1985; VERGER, Pierre. Fluxo e Refluxo do Tráfico de Escravos entre o Golfo do Benim e a Bahia de Todos os santos. Dos séculos XVII a XIX. 3a ed. São Paulo: Editora Corrupio, 1987; RODRIGUES, Jaime. $O$ Infame Comércio: Propostas e Experiências no final do tráfico de Africanos para o Brasil (1800-1850). Campinas: Editora da Unicamp, Cecult, 2000; BLACKBURN, Robin $A$ queda do Escravismo Colonial: (1776-1848). Rio de Janeiro, Record, 2002.

7

Ver: ALEXANDRE, Valentim. Os Sentidos do Império: Questão Nacional e Questão Colonial na Crise do Antigo Regime Português. Porto: Edições Afrontamento, 1993; Idem, "O Império Luso-Brasileiro em face do abolicionismo inglês. (1807-1820)", in: SILVA, Maria. B. Nizza. da. (org) Brasil. Colonização e escravidão. Rio de Janeiro: Editora Nova Fronteira, 2000; MARQUES, João. P. Os Sons do silêncio. 0 Portugal de oitocentos e a Abolição do tráfico de escravos. Lisboa: Imprensa de Ciências Sociais, 1999; FERREIRA, Dóli C. Tomás Antônio Vilanova Portugal: um ministro de D. João VI 1817-1821. São Paulo, Dissertação de Mestrado USP, 2004; SILVA, Alberto da Costa e. Um Rio chamado Atlântico. África econômicas presentes no Atlântico-Sul. Rio de Janeiro: Nova Fronteira; EDUFRJ, 2003.

Valentim Alexandre, Os Sentidos do Império: Questão Nacional e Questão Colonial na Crise do Antigo Regime Português. Porto: Afrontamento, 1993, pp. 356. oficios de embaixadores e de funcionários de primeiro escalão despachados aos secretários da pasta de Negócios Estrangeiros e da Guerra do governo de D. João. Entre os embaixadores portugueses em Londres destacam-se Cipriano Ribeiro Freire, embaixador português durante o ano de 1816; o Conde de Palmela, embaixador e plenipotenciário português, entre outubro de 1816 a 1818; e Rafael da Cruz Guerreiro, provavelmente, secretário da Embaixada e autor de ofícios datados a partir de 1818 e 1819. Além dos ofícios, a documentação pertencente ao Arquivo Histórico do Itamaraty também possibilitou a leitura de Quadros Políticos, espécie de relatórios que continham uma análise política da Europa, redigidos por Rafael da Cruz Guerreiro entre 1816 a 1819.

Enquanto as fontes dos arquivos cariocas permitem a leitura de documentos elaborados por órgãos do Estado português, as fontes pertencentes à Biblioteca do Instituto de Estudos Brasileiro/USP possibilitam a leitura de jornais portugueses publicados em Londres no início do século XIX. Dentre os jornais portugueses utilizados para elaboração da pesquisa estão o Investigador Portuguez em Inglaterra e o Correio Braziliense ou Armazém Literário ${ }^{5}$. Seguindo orientações diversas, é possivel encontrar reflexões dos responsáveis dos jornais sobre o tráfico de escravos e a repercussão da assinatura da Convenção de 1817 no Império Português.

\section{Desenvolvimento da pesquisa}

0 documento ratificado entre a Corte de D. João e a Grã-Bretanha, em 1817, foi arrolado, por parte da historiografia referente ao tema do tráfico de escravos, como uma evidência ou um fato em um contexto mais amplo de debates sobre a escravidão no novo mundo. Predominantemente, a Convenção de 1817 se fez presente mais como um argumento que ressaltava a pressão inglesa como fator principal do processo de supressão do tráfico no Brasil. Assim, a Convenção, ou melhor, as decisões políticas tomadas no Rio de Janeiro em relação ao tráfico de escravos, no governo joanino, seriam determinadas pela pressão exercida pela Inglaterra, calcada em uma nova conjuntura econômica instaurada pela Revolução Industrial ou mesmo pela ação humanitária inglesa ${ }^{6}$.

Outra parte da historiografia apresenta a discussão sobre a extinção do tráfico sob a perspectiva de projetos políticos elaborados no Império Português, particularmente, os projetos suscitados por D. João VI na América7. A partir disso, as propostas inglesas sobre a abolição do tráfico seriam recebidas pelos estadistas portugueses como elemento de barganha internacional diante de movimentos políticos empreendidos pela Corte no Rio de Janeiro. Desse modo, a Convenção de 1817 e a concessão do direito de visita aos navios britânicos, por ela estipulado, seriam uma tentativa da Corte lusitana assegurar uma eventual garantia do apoio britânico diante da invasão das tropas portuguesas aos territórios espanhóis na "Banda Oriental do Prata"8. Nesse sentido, as negociações sobre a abolição do tráfico de escravos e a possibilidade de execução de acordos bilaterais sobre esta prática mercantil envolveriam uma variedade de interesses políticos no interior da Monarquia Portuguesa e da própria posição que a Coroa Lusitana ocupava diante do contexto político internacional. Nessa ótica, portanto, a análise da questão política em relação à Convenção de 1817 adquire uma dimensão mais ampla do que a interpretação da presença hegemônica inglesa deixa entrever. 
Ver: ALENCASTRO, Luis Felipe de 0 Trato dos Viventes. A formação do Brasil no AtlânticoSul. São Paulo: Cia das Letras, 2000; SILVA, Alberto da Costa e. Um Rio chamado Atlântico. África no Brasil e o Brasil na África. Rio de Janeiro: Nova Fronteira; EDUFRJ, 2003; Idem, Francisco Felix de Souza. Mercador de Escravos. Rio de Janeiro: EDUERJ; Nova Fronteira, 2004; MARTINHO, Lenira Menezes \& GORENSTEIN, Riva. Negociantes e Caixeiros na sociedade da Independência. Rio de Janeiro: Secretaria Municipal de Cultura, 1993; FLORENTINO, Manolo Garcia. Em Costas Negras: uma história do tráfico de escravos entre África e o Rio de Janeiro: séculos XVIII e XIX. São Paulo: Cia das Letras, 1997; FRAGOSO, João Ribeiro \& FLORENTINO, Manolo. 0 Arcaísmo como Projeto. Mercado Atlântico, sociedade agrária e elite mercantil no Rio de Janeiro, c. 1790 - c. 1840 . Rio de Janeiro: 7 letras, 1998.

\section{0}

Coleção das Leis do Brasil, Carta de Lei de 08/05/1815. Ratificação do Tratado entre o Príncipe Regente e o Rei da Grã-Bretanha, assinado em Viena em 22 de janeiro de 1815 para a abolição do tráfico de escravos.

11

Idem, Carta de Lei de 08/11/1817. Ratificação da Convenção Adicional ao Tratado de 22 de janeiro de 1815, assinada em 28 de julho de 1817 em Londres.

\section{2}

Idem, Carta de Lei de 08/05/1815. Ratificação do Tratado entre o Príncipe Regente e o Rei da Grã-Bretanha, assinado em Viena em 22 de janeiro de 1815 para a abolição do tráfico de escravos.
Contudo, a leitura da bibliografia identificou também a pertinência de uma abordagem sobre os acordos assinados por D. João com a Inglaterra, entre eles a Convenção de 1817, que levasse em consideração a importância econômica que os traficantes de escravos possuiam no Rio de Janeiro, financiando empreendimentos econômicos e imobiliários 9 . A questão é: como setores tão importantes para o sistema de crédito do Atlântico-Sul e também importantes para a reorganização do Estado e sustentação da Coroa na América lidaram com as estipulações negociadas pela Corte joanina sobre o tráfico de escravos. Assim, procuramos evidenciar a maneira pela qual a documentação expõe a pressão inglesa e a negociação dos interesses "portugueses" diante do tráfico. Além disso, buscamos identificar os argumentos utilizados pela Coroa Lusitana sobre o tráfico de escravos, a partir da assinatura da Convenção de 1817, e relacioná-los com a conjuntura política e econômica do então Reino de Portugal, Brasil e Algarves.

Diante disso, o estudo da "Convenção Adicional ao Tratado de 22 de janeiro de 1815, entre o Príncipe Regente Português e o Rei da Grã Bretanha, para a abolição do tráfico de escravos ao norte do Equador", assinada em 28 de julho de 1817, se inicia pelo questionamento do próprio título do documento. 0 que foi adicionado ao tratado firmado ainda no Congresso de Viena e por que foi preciso acrescentar ou mudar os termos e estipulações?

Algumas hipóteses poderiam ser formuladas levando em consideração o artigo IV do Tratado de 22 de janeiro de $1815^{10}$ no qual as duas nações se comprometiam a elaborar um "outro Tratado para abolir universalmente 0 tráfico". Entretanto, ao contrário deste artigo, a Convenção de 1817 ainda permitia o tráfico ao sul da linha do Equador, buscando, apenas, regulamentar e cumprir rigorosamente o que havia sido estipulado ainda em Viena ${ }^{11}$. Dessa forma, a Convenção, formulada de modo mais detalhado em comparação com o artigo X do Tratado de Aliança e Amizade de 1810 e com o Tratado de 22 de janeiro de 1815, especificava os lugares lícitos ao comércio de escravos - por referências cartográficas (latitude) ou designação nominal - e estabelecia o direito de visita, tanto de navio português quanto britânico, aos supostos traficantes de uma ou outra nação que atuassem na zona proibida.

Porém, grande parte da elaboração do documento de 1817 dependeu de questões que surgiram entre o governo Português e Inglês diante da execução do artigo II e do artigo V presentes no Tratado de 181512, além do cumprimento da Convenção de 1815 também assinada entre os dois governos em Viena. Por sua vez, o artigo II do documento de 1815 atribuía ao governo português a responsabilidade de implementar medidas para regular a proibição do tráfico ao norte da linha do Equador. Já o artigo V e a Convenção estipulavam que o governo britânico desistiria de cobrar um empréstimo de 600 mil libras, feito em 1809, pela Monarquia Lusitana e se comprometeria a pagar uma indenização de 300 mil libras pelos apresamentos feitos pela marinha inglesa desde 1811 a junho de 1814, respectivamente. Entretanto, enquanto o governo português cobrava do governo britânico o cumprimento do artigo $V$ e da Convenção de 1815, o governo britânico se negava a cumprir o que estabelecia o referido termo caso D. João não regulamentasse penas para os traficantes portugueses que não respeitassem o tratado, de acordo com o artigo II. Os obstáculos, portanto, 
para a execução total do acordo de 22 de janeiro de 1815 ainda permaneciam em vigor e a Convenção elaborada em 1817 tinha por objetivo a remoção destas barreiras.

A leitura da Correspondência da Legação Portuguesa em Londres apresenta a longa negociação que se estabeleceu entre os governos de Portugal e da Grã-Bretanha após a ratificação do Tratado de 22 de janeiro ocorrida em junho de 1815. A documentação mostra os empecilhos com que cada representante de governo se deparava; os argumentos utilizados, por um ou por outro embaixador, diante das questões estipuladas no Tratado e Convenção de 1815; e o contexto político que permitia as investidas tanto de um quanto de outro lado no convencimento das alegações de cada Coroa.

Os ofícios formulados por Cipriano Ribeiro Freire - embaixador português durante a maior parte do ano de 1816 em Londres - ao Marquês de Aguiar - Secretário dos Negócios Estrangeiros e da Guerra no Rio de Janeiro - esboçam as questões suscitadas acima. Ao longo do ano de 1816, a correspondência de Ribeiro Freire versou sobre diligências que empreendeu junto ao ministro inglês, Lord Castlereagh, secretário dos Negócios Estrangeiros da Coroa Britânica, para a quitação da dívida contraída pela Inglaterra no Tratado de 1815. Sempre considerando Portugal como a nação que cumpria as determinações do Tratado, Freire não poupou esforços para debater sobre os termos e as obrigações de cada nação em conferências ora com Lord Castlereagh ora com Mr. Hamilton, sub-secretário da mesma pasta, e ainda com o Advogado e Procurador da Coroa Britânica, Mr. Plant.

Freire argumentava levando em consideração os artifícios jurídicos que obrigavam uma ou outra nação a cumprir as determinações acordadas desde o Tratado de 1815. Para ele, "quando Tratados entre nações eram ratificados, eles eram considerados documentos perfeitos, não podendo uma das partes invalidar a sua execução". Desse modo, o governo português pressionava o britânico pelo pagamento da indenização das 300 mil libras e pelo fim da cobrança do empréstimo de 600 mil libras. A argumentação de Freire, fundamentando-se nas estipulações do tratado, desqualificava o argumento inglês, dizendo que a pressão da Inglaterra em obrigar Portugal a elaborar leis aos traficantes que desrespeitassem o acordo de 1815 constituia mais uma cláusula evasiva e um subterfúgio. É interessante notar que o governo português assumia a estipulação, ao menos nominal - e isso deve ser levado em consideração - do Tratado que proibia o fim do tráfico ao norte do Equador. A documentação, portanto, permite a abertura de novos problemas sobre a postura de D. João diante do tráfico e dos tratados firmados com a Inglaterra. Assim, a linha política adotada pelos embaixadores não se mostrava uma reação à ação inglesa e muito menos na compreensão de que os tratados, firmados ao longo da segunda década do século XIX, imobilizavam a ação dos portugueses no tráfico de escravos. Pelo contrário, a documentação permite lançar a hipótese de que a diplomacia lusitana utilizava os próprios artifícios presentes nos tratados já ratificados como uma maneira de prorrogar a execução das ações previstas.

A correspondência de Freire revela ainda o fluxo de informação que envolvia os dois governos. A Corte do Rio de Janeiro, através da correspondência de seus diplomatas em Londres, possuía ciência do contexto político interno à Inglaterra, seja a relação do governo com os agentes da campanha anti-tráfico, seja o conteúdo que as gazetas inglesas publicavam sobre os 
13

Arquivo Histórico do Itamaraty, Legação Portuguesa em Londres. Correspondência do Conde de Palmela ao Marquês de Aguiar e ao Conde da Barca (1816 e 1817). Loc: Estante:338, Prateleira: 1, Volume:17. Ofício $n^{\circ} 08$. Londres 10 de dezembro de 1816.
14

Arquivo Histórico do Itamaraty, Legação Portuguesa em Londres. Correspondência do Conde de Palmela ao Marquês de Aguiar e ao Conde da Barca (1816 e 1817). Loc: Estante:338, Prateleira: 1, Volume:17. Ofício $n^{\circ} 14$. Londres 10 de fevereiro de 1817. interesses dos "vassalos" do governo português na Inglaterra. Nesse sentido, as instruções para a elaboração da Convenção de 1817 não seriam fruto da ação inglesa, mas sim de jogo político, onde todas as variáveis estavam expostas e as duas partes tinham conhecimento das possibilidades e limites da ação de cada uma.

Por outro lado, em detrimento da tática jurídica utilizada por Freire, a estratégia do Conde de Palmela, que assumiu a embaixada portuguesa a partir de outubro de 1816, procurava compreender o contexto internacional e relacioná-lo com possiveis defesas da manutenção do tráfico de escravos e, assim, obter o cumprimento dos acordos firmados em Viena por parte da Inglaterra. Na verdade, os dilemas gerados pelo tráfico eram considerados pelo Conde apenas como mais um componente do espaço Atlântico. Para Palmela, a manutenção do tráfico de escravos dependia muito de um acordo diplomático entre as nações, principalmente daquelas que não estavam diretamente ligadas às rotas entre a América e a África como era o caso de Rússia, Prússia e Áustria. 0 peso diplomático que tais nações possuiam no continente europeu e o bom arranjo político que Portugal viesse a concluir com uma dessas potências continentais poderiam proporcionar amparo às pretensões portuguesas sobre o tráfico de escravos frente à Grã-Bretanha. Ainda que o apoio das potências continentais à causa inglesa fosse declarado, como era o caso da Rússia, tais atos eram interpretados pelo embaixador português mais como ponto de conveniência política do que algum princípio de valor. Nesse ambiente de arranjos diplomáticos que visavam a garantir a implementação de projetos políticos, tanto do lado britânico quanto do português, a negociação do casamento de D. Pedro com a D. Leopoldina adquiriu grande importância nas discussões diplomáticas dirigidas pelos embaixadores lusitanos. Na leitura da correspondência, é clara a intenção de Palmela de evitar o isolamento de Portugal nas discussões do concerto Europeu. A junção do governo português com o governo austríaco, através do casamento dos seus descendentes, se colocava como uma alternativa de reorganização geopolítica, a qual poderia ter conseqüências em diversos setores portugueses, inclusive o tráfico ${ }^{13}$. Portanto, não parece pertinente entender a segunda década do século XIX como um periodo no qual a diplomacia portuguesa foi refém das demais nações e, principalmente, da Inglaterra diante da questão do tráfico. 0 jogo diplomático exposto por Palmela era aberto e Portugal não apresentava uma postura passiva diante dos interesses diversos de outras nações.

Embora os possiveis arranjos diplomáticos entre Coroa Lusitana e demais nações fossem considerados preponderantes para as negociações bilaterais entre Portugal e Grã-Bretanha, eles não tinham por único objetivo obstaculizar as ações inglesas sobre o tráfico de escravos. Pelo contrário, os possiveis arranjos acabavam proporcionando a Portugal condições de impor e salvaguardar seus interesses em relação ao Atlântico-Sul. Não é à toa que Palmela inicia o seu ofício de resposta ao despacho que continha as instruções do futuro acordo de 1817, dizendo que o objetivo da futura convenção era o de continuar o tráfico, abastecendo de "braços o Brasil" e evitando "os insultos e prejuizos que, contra todo o direito, nos causam os cruzadores Britânicos ${ }^{14 "}$. Assim, outra hipótese a ser desenvolvida é o fato de que a Convenção foi, pelo menos em parte, uma demanda da própria Corte na América, buscando a regularização das atividades dos traficantes no Atlântico, sem embaraços da marinha Inglesa. Novamente, o documento que foi considerado como mais um passo visando a abolição do tráfico, 
aparece como uma tentativa de legalização da própria prática traficante, regulamentando a sua atividade sem deixar margem para que empecilho algum fosse colocado em sua dinâmica.

Por fim, o questionamento da elaboração da Convenção de 1817 pode revelar questões inéditas ou pouco exploradas sobre o tráfico e sobre a posição do governo joanino frente a essa prática mercantil. Desse modo, a partir do estudo da Convenção, é possível reconstituir o ambiente político do governo de D. João na América, particularmente entre 1817 e 1818, momento marcado por amplo debate seja em torno do tráfico seja em termos do futuro da Monarquia portuguesa, como indicaram as revoluções de 1817 em Pernambuco e em Portugal. 